DOI 10.37882/2223-2982.2020.12.28

\title{
ИНОСТРАННАЯ ЛЕКСИКА В СОВРЕМЕННОМ НЕМЕЦКОМ ЯЗЫКЕ В КОНТЕКСТЕ ЗАИМСТВОВАНИЯ И СЛОВООБРАЗОВАНИЯ
}

\section{FOREIGN VOCABULARY IN MODERN GERMAN LANGUAGE IN THE CONTEXT OF BORROWING AND WORD FORMATION \\ V. Panfilova \\ A. Gazizova}

Summary: Vocabulary is the main aspect of any language from a psychological point of view. This is due to the fact that without knowledge of words and in the absence of vocabulary, one cannot speak of proficiency in one language or another. In this work, the authors study and analyze modern foreign vocabulary in the modern language in the context of word formation and borrowing. The traditional ways of forming words in the German language are considered, the main trends of modernization, development and changes in the modern language are identified and described. The process of borrowing foreign vocabulary is analyzed, through which mechanisms this process is implemented.

Keywords: vocabulary, word formation, borrowing, foreign words, German.

\author{
Панфилова Валентина Михайловна \\ К.п.н., дочент, Казанский федеральный университет \\ valova55v@yandex.ru \\ Газизова Альфия Ильдусовна \\ Д.п.н., профессор, Казанский национальный \\ исследовательский технический университет \\ им. А.Н. Туполева-КАИ \\ Alfgazva@mail.ru
}

Аннотация: Лексика представляет собой главный аспект любого языка с психологической точки зрения. Это объясняется тем, что без знания слов и при отсутствии словарного запаса нельзя говорить 0 владении тем или иным языком. В работе авторы исследуют и анализируют современную иностранную лексику в современном языке в контексте словообразования и заимствования. Рассмотрены традиционные способы образования слов в немецком языке, выявлены и описаны основные тенденции модернизации развития и изменения современного языка. Проанализирован процесс заимствования иностранной лексики, посредством каких механизмов реализуется данный процесс.

Ключевые слова: лексика, словообразование, заимствование, иностранные слова, немецкий язык.

Изучение способов словообразования и методов заимствований иностранных слов, а также изучение интернационализмов является наиболее результативной и эффективной формой усвоения новых слов, способом обогащения и развития словарного запаса.

Целью данной работы является рассмотрение способов словообразования и заимствования иностранных слов в современном немецком языке, анализ процессов и тенденций, которые сегодня можно заметить в изменении немецкой лексики.

\section{Основная часть}

Каждый язык обладает собственной совокупностью методов и средств словообразования. Данная система варьируется и отличается в зависимости от того, насколько продуктивны и эффективны те или иные методы, решения, способы. Если говорить о словообразовании немецкого языка, данный процесс является особым разделом языкознания, который посвящен изучению словесных структур и законов их образования, изменения $[3,4]$.

Рассмотрим традиционные способы словообразования современного немецкого языка:

1. Морфолого-синтаксический. 
2. Словосложение.

3. Морфологический.

4. Лексико-синтаксический.

Ряд немецких исследователей считают, что ведущую роль в процессе словообразования на текущем этапе развития играет такой способ как словосложение. Наибольшей эффективностью он обладает в разрезе существительных с широким разнообразием морфологического состава $[5,6]$.

Разберем каждый из перечисленных способов более подробно.

1. Морфолого-синтаксический способ. Заключается в образовании новых слов посредством перехода того или иного грамматического класса в другой. Подразумевает под собой адвербиализацию, субстанцивацию и адъективацию.

2. Словосложение. Метод заключается в образовании новых слов (речь идет о композитах или сложных словах), которые получаются в результате соединения двух и более основ или слов. На данный момент способ покрывает все части речи и является наиболее продуктивным способом.

3. Морфологический способ. Подразумевает присоединение специализированных аффиксальных морфем к словесной основе или целому слову. В данном случае можно говорить об аффиксальном словопроизводстве, которое подразумевает использование префиксально-суффиксального метода, присоединение префиксов и суффиксов.

4. Лексико-синтаксический метод. Наиболее сложная техника, так как подразумевает соединение в одно слово целого выражения или сочетания. Посредством лексико-синтаксического метода, как правило, образуются неологизмы. К примеру, рост активности террористических организаций привел к появлению в немецком языке следующих слов: der Anti-Terror-Krieg, der Schläfer, die Milzbrandattacke.

Сегодня на фоне всемирной глобализации можно наблюдать интернационализацию лексики различных стран мира. Важно отметить, что интернационализируется не только словарный запас, но и методы словообразования, способы объединения морфем в цельные слова. Таким образом, перед современными лексикологами стоит важная задача: квалифицировать иностранные слова как словообразовательное производное или как заимствование. Задачу не всегда можно решить однозначно, так как она решается на фоне интернационализации $[7,8,9]$.

Согласно данным орфографического языка немецкого языка Дудуен, который публиковался с 1880 до 1996 года, по состоянию на 1996 год словарный состав немецкого языка включает в себя от 400000 до 500000 фразеологизмов и слов. При этом активный словарный запас носителя немецкого языка составляет от 15000 до 20000 слов. Пополнение словарного запаса происходит посредством следующих способов:

1. Словобразование (неологизмы составляют 83\% от всех новых слов).

2. Изменение смысла слов, приобретение новых значений (13\% всех вводимых слов).

3. Заимствования из иностранных языков (4\%) [10].

Для оценки значимости иностранной лексики, которая сегодня является неотъемлемой частью современного немецкого языка, необходимо обратиться к перечню «Сто слов XX века». Это список включает наиболее значимые слова и выражения, которые имели особую значимость в течение XX века. Список отражает выдающиеся события и понятия культурной, общественной, экономической, политической и других сфер жизни Германии. Перечислим несколько примеров с русскоязычным переводом:

1. Friedensbewegung - общественное движение в защиту мира.

2. Kalter Krieg - холодная война.

3. Völkerbund - конвейер.

4. Völkerbund - Лига инаций.

5. Weltkrieg - мировая война.

6. Werbung - реклама [11].

В результате сопоставления не только приведённых слов, но также и других слов, входящих в перечень, можно обнаружить, что зачастую немецкому слову в русской речи соответствует иностранное слово (например, «реклама» или «конвейер»).

Таким образом, современную лексику немецкого языка можно поделить на две категории:

1. Эндогенная, имеющая внутреязычное происхождение. В данную категорию входят исконно немецкие слова, которые имеют германские корни. На их долю приходится 1/3 часть лексики. Как правило, они образуются в результате словообразования, преимущественно словосложения. К примеру, Luftkrieg (воздушная война) и Blockwart (доверенное лицо). Также для их образования может использоваться такой метод как словопроизводство. К примеру, слово «Säuberung», которое переводится как «чистка» образовано посредством суфиксации; слово «Urknall», которое переводится как «взрыв вселенной» образовано посредством метода префиксации.

2. Экзогенная, имеющая внешнее происхождение. Экзогенная лексика подразумевает иностранную лексику, которая не свойственная немецкому языку. В данную категорию входят заимствованные слова, которые ассимилированы с немец- 
ким языком (примеры: «Sport», «Film»); интернационализмы, которые отличаются наличием таких суффиксов как «-tion» и «-іsmus» (примеры: «Manipulation», «Sozialismus»). Если при анализе экзогенной лексики встречаются затруднения при отнесении слова к заимствованиям или интернационализмам, необходимо обращаться к этиологии рассматриваемого слова. К примеру, проведя этимологическое исследование таких слов как «Originalität», «Sentimentalität» и «Polarität», было выявлено, что последнее относится к эндогенной лексике, так как образовано в немецком язык, в отличие от остальных, которые произошли во французском языке, а затем были заимствованы.

В разрезе изучения иностранной лексики в современном немецком языке с учетом заимствований и способов словообразования, необходимо разобрать вопрос авторства внедренных иностранных слов. Сегодня известен ограниченный перечень слов, которые можно отнести к категории авторских, то есть доподлинно известен их автор. Ярким примером является слово «Vitamin» (переводится на русский язык как «витамин»), созданное биохимиком из США - Казимиром Функом. В последующем слово было заимствовано многими языками мира, в том числе немецким и русским.

Рассматривая современные языковые тенденции XXI века, посредством которых осуществляется формирование глобализированного мирового пространства, необходимо выделить:

1. Интернационализацию лексики всех языков в целом и немецкого языка в частности.

2. Сохранение самобытного словарного запаса, которое сопровождается рядом трудностей.

В рамках первой тенденции необходимо использовать такое понятие как интернационализм, который представляет собой языковую единицу, различные вариации которой встречаются в 3 и более современных языках, генетически отличающихся друг от друга. К интернационализмам относятся:

1. Интерлексемы.

2. Интрефраземы или интерфразеологизмы.

Если оценивать количество иноязычных слов, которые сегодня присутствуют в современном немецком языке, их количество и доля несущественно отличаются от аналогичных показателей XX или XIX веков. Это объясняется процессами обогащения и устаревания лексического запаса, который протекает без остановок и перерывов независимо от мировых и внутригосударственных социально-политических, экономических, культурных и прочих процессов. Сегодня обновление лексики реализуется посредством:
1. Прямых заимствований из средств массовой информации и сети Интернет. Как правило, это термины из области экономики и спорта. Проведенные исследования говорят о том, что из всех языков стран Европейского Союза, немецкий больше всего подвержен влиянию англоязычных слов и выражений.

2. Семантической деривации.

3. Образования новых слов, включающих элементы из английского языка. К примеру, «тур все включено 2 сегодня на немецком языке звучит как «Allinclusive-Reise».

4. Кальки неологизмов. К примеру, англоязычный термин «рау TV», который переводится как «платное телевидение» в немецком языке приобретает следующую форму неологизма: «Bezahl-TV».

5. Образование псевдозаимствованных неологизмов. Ярким примером является слово «Handy», которое переводится как «сотовый телефон».

Важно учитывать, что кроме активного внедрения в современный немецкий язык посредством заимствований и словообразования, иностранная лексика составляет $1 / 4$ часть от объема устаревающих слов, которые сегодня выходят из активного употребления. В данном процессе отчетливо можно проследить следующий тренд: архаизация лексики, как эндогенной, так и экзогенной, реализуется преимущественно посредством вытеснения немецких слов иностранными словами, которые вызывают затруднения при произношении и написании даже у носителей языка. Все архаизмы при этом можно разделить на следующие категории:

1. Редко употребляемые слова. К примеру, «Aroma» встречается в СМИ и интернете гораздо чаще, чем «Duft», которое сложнее в плане произношения. Это привело к тому, что второе слово сегодня используется крайне редко.

2. Слова, которые имеют несколько значений. Здесь есть важная особенность: если устарело одно из значений, слово может использоваться в разрезе остальных семантических смыслов. К примеру, слово «Affäre» сегодня преимущественно поменяется для передачи таких событий как «скандал» или «неприятная ситуация». А вот в значении «любовная связь» оно уже практически не применяется.

3. Фразеологизмы, которые имеют в своем составе лексемы иностранного происхождения.

4. Клише, которые были заимствованы из других языков. Примечательно, что в данном случае клише из одного иностранного языка могут вытесняться клише из других зарубежных языков.

Говоря о заимствовании иностранной лексики, необходимо рассмотреть наиболее распространенные варианты семантической структуры слова в языке, который 
является реципиентом.

Чаще всего заимствуются только некоторые значения многозначных слов. В ряде случаев слово или выражение может приобретать дополнительное значение, которого нет в донорском языке. Ярким примером является английское слово «Single», которое в донорском языке обозначает:

1. Одинокого человека, без спутника жизни.

2. Одиночный спортивный разряд.

3. Билет в одном направлении, без обратного направления.

4. Номер на одного в отеле.

5. Купюра, номинал которой составляет единицу.

В немецкоязычных словарях данный англицизм имеет несколько иные значения:

1. Одиночный спортивный разряд, но только в контексте профессионального бадминтона или тенниса.

2. Музыкальная пластинка, с каждой стороны которой имеет только по 1 произведению.

3. Одинокий мужчина или женщина, которые не женаты/не замужем.

Вторая тенденция при заимствовании - полное игнорирование многозначности. К примеру, в языке-доноре слово «Drink» имеет 6 смысловых значений, а при заимствовании в немецкий язык за ним сохраняется только один смысл - «алкоголь».

Третья тенденция - обретение новых стилистических особенностей в контексте языка - рецепиента. K примеру, словесная пара немецкого слова «Arbeit» и английского «Јob» изначально имели одно значение - «работа». Однако после заимствования второго в немецком языке оно начало использоваться как «подработка или деятельность по совместительству». При этом существует термин «Beruf», обозначающий приобретенную профессию.

\section{Зак^ючение}

На основании выполненного исследования можно сделать вывод, что современный немецкий язык, с его экзогенной и эндогенной лексикой, был сформирован и продолжает развиваться в результате постоянного обогащения новыми словами, а также в результате архаизации лексики. Сегодня отчетливо прослеживается тренд на интернационализацию лексики на фоне мировой глобализации, что проявляется в виде активного вплетения иностранной лексики посредством заимствования и образования новых лексических единиц.

При исследовании и анализе иностранной лексики особую ценность представляют лексические единицы, которые трансформируются в узус, то есть их активным образом использует языковой коллектив.

\section{ЛИТЕРАТУРА}

1. Бим И.Л., Рыжова Л.И., Садомова Л.В. и др. Немецкий язык. Сборник примерных рабочих программ. Предметная линия учебников И.Л. Бим. 2-11 классы. М.: Просвещение, 2018. С.336.

2. Степанова М.Д. Словообразование современного немецкого языка. М.: КомКнига, 2007. 376 с.

3. Sahel S. Einführung in die Morphologie des Deutschen [Elektronische Ressource] Wissenschaftliche Buchgesellschaft, 2013. Режим доступа: https://www.goethe. de/ins/ru/ru/kul/ser/onl.html (Дата обращения: 06.11.2020).

4. Schröder M. Wortbildung der deutschen Gegenwartssprache /Wolfgang Fleischer; Irmhild Barz. Schröder, Marianne. Tübingen: Niemeyer, 2007. Режим доступа: https://www.goethe.de/ins/ru/ru/kul/ser/onl.html (Дата обращения: 06.11.2020).

5. Heringer H.J. Deutsche Grammatik und Wortbildung in 125 Fragen und Antworten [Elektronische Ressource] UTB, 2014. Режим доступа: https://www.goethe.de/ ins/ru/ru/kul/ser/onl.html (Дата обращения: 05.11.2020).

6. Luscher R. Übungsgrammatik für Anfänger (DaF) [Elektronische Ressource]: Deutsch als Fremdsprache Hueber, 2011. Режим доступа: https://www.goethe.de/ ins/ru/ru/kul/ser/onl.html (Дата обращения: 05.11.2020).

7. К Крысин Л.П. Русское слово, свое и чужое: Исследования по современному русскому языку и социолингвистике. - М.: Языки славянской культуры, 2004. - 888 с.

8. Крысин Л.П. Толковый словарь иноязычных слов. - М.: Эксмо, 2005. - 944 с.

9. Крысин Л.П. Этапы освоения иноязычного слова // Русский язык в школе. 2006. № 2. С. 74-78.

10. 1Duden online (нем.). (https://www.duden.de). Дата обращения: 06.11.2020.

11. Die hundert Wörter des XX. Jahrhunderts. - Режим доступа: http://de.wikipe dia. org/wiki/100_Wörter_des_Jahrhunderts. Дата 0бращения: 05.11.2020.

(c) Панфилова Валентина Михайловна (valova55v@yandex.ru), Газизова Альфия Ильдусовна (Alfgazva@mail.ru).

Журнал «Современная наука: актуальные проблемы теории и практики» 